\title{
The importance of phenotypic diversity in conservation: resilience of palmate newt morphotypes after fish removal in Larzac ponds (France)
}

\author{
Mathieu Denoël*, Laurane Winandy \\ Laboratory of Fish and Amphibian Ethology, Behavioural Biology Unit, Department of \\ Biology, Ecology and Evolution, University of Liège, Belgium
}

*Corresponding author. Email address: Mathieu.Denoel[a]ulg.ac.be

\begin{abstract}
Resilience of organisms after threat removal is an essential feature to justify conservation efforts. Amphibians are particularly threatened with a worldwide decline, showing a low resistance to invaders such as fish. Previous research has shown that they could recover after fish extirpation due to metamorphosed colonizers. However, not all amphibian phenotypes are able to persist after fish introduction and disperse. In many species of newts and salamanders, paedomorphs retain gills in the adult stage, which makes them fully aquatic. A proposed way to conserve this phenotype would be to remove introduced fish from their habitats. However, because paedomorphosis is usually not expressed in the presence of fish, it is unknown whether fish removal could allow the resilience of paedomorphs. This would be possible only if progenies of metamorphosed individuals could become paedomorphic in restored habitats. Through a quantitative survey in three types of ponds, including control ponds without fish, ponds in which fish were extirpated, and fish ponds, we determined abundances of paedomorphic and metamorphic palmate newts (Lissotriton helveticus). The results show that paedomorphosis resilience is possible and even highly frequent, as paedomorphs were found in $80 \%$ of ponds where fish disappeared. Abundances were similar between these ponds and control ponds whereas fish ponds had almost no newts, indicating a very low resistance to invaders. This shows that conserving common phenotypes can help to preserve endangered phenotypes, as paedomorphs were produced through the reproduction of metamorphs. There is thus hope of maintaining intraspecific biodiversity though conservation action involving threat removal.
\end{abstract}

Keywords

Amphibian decline

Facultative paedomorphosis

Fish introduction

Fish removal

Invasive species

Resilience

*Corresponding author. Email address: Mathieu.Denoel[a]ulg.ac.be 


\section{Introduction}

The populations of many organisms exhibit variations such as local specialisations, the persistence of ancestral traits, genetically and environmentally induced polymorphisms (WestEberhard 2003; Baker et al. 2010). These phenotypes are often seen as evolutionary significant units that are an inherent component of biodiversity (Fraser and Bernatchez 2001; Moritz 2002). Although some phenotypes can be abundant, common and widespread over large geographic ranges, others can be rare and localised, and thus, are more likely to suffer global decline. Moreover, some phenotypes are particularly adapted to specific environmental conditions and when these conditions deteriorate, such as following anthropogenic pressures, they could be more at risk than more tolerant phenotypes (Hendry et al. 2006; Denoël 2007; Lescak and von Hippel 2011). For instance, in sticklebacks, specialised phenotypes show a pelvic reduction that is considered to be the result of their evolution in a predator-free environment. In contrast to the less endangered armoured phenotypes, these phenotypes are now exposed to a high risk of predation from large introduced fish species that contribute to their decline (Von Hippel 2008; Baker et al. 2010; Lescak and von Hippel 2011).

Paedomorphosis in newts and salamanders provide a particularly interesting example of phenotypic diversity with conservation relevance. Most pond-breeding species exhibit facultative paedomorphosis in some of their populations. This means that two phenotypes can coexist: metamorphs that can live on land but need water to breed and paedomorphs that retain larval traits, such as gills at the adult stage, and stay aquatic. This is an adaptive process that is driven by heterochrony, i.e., changes in the time or rate of development between phenotypes (Gould 1977; Denoël et al. 2005b). The rarest paedomorphic phenotype can exploit specific resources and mature at an early age by avoiding the costs of metamorphosis, but is highly endangered by disturbance of its aquatic habitat, such as alien fish introductions (Denoël et al. 2005a; Denoël 2007). Similarly to sticklebacks, which cannot leave water, paedomorphs are thus constrained to share the same habitats as introduced fish (Denoël et al. 2005a). As a consequence, the populations of salamandrid paedomorphs have declined, with extinctions being recorded in almost $50 \%$ of populations at the continental scale in Europe (Denoël et al. 2005a). Similar reports were also made for other families, such as facultatively paedomorphic ambystomatids in Northern America (Whiteman and Howard 1998). The most famous example is without any doubt the axolotl (Ambystoma mexicanum), a nearly obligate paedomorphic species, which is now at the edge of extinction in the wild because of fish introductions and the destruction of its aquatic habitat (Contreras et al. 2009; Zambrano et al. 2010).

Similar to the two above-mentioned examples, the introduction of alien species is one of the main causes of biodiversity loss (McGeoch et al. 2010). Among the large variety of alien taxa involved, fish occupy a primary role due to the global scale of their introduction (Cambray 2003). Fish introductions particularly affect native species, such as many species of amphibians, which usually live in habitats that are naturally devoid of fish (Cox and Lima 2006; Salo et al. 2007). As a consequence, amphibians often become extinct or show reduced abundances in the presence of fish (Kats and Ferrer 2003). Together with other local and global causes, such as habitat alteration and destruction, pollution and emerging diseases, these fish introductions cause amphibian populations to decline at such an unprecedented rate that they are involved in the sixth world mass extinction (Stuart et al. 2004; Wake and Vredenburg 2008).

Despite their low resistance to environmental disturbance such as fish introductions, amphibians can also show a high degree of resilience, i.e., the ability to return to their previous configuration once the perturbation is removed (Knapp et al. 2001). For instance, the removal of fish from lakes allowed the restoration of frog and salamander populations (Vredenburg 2004; Knapp et al. 2007; Pope 2008). This resilience was enhanced in many species of bi-phasic 
amphibians that are able to disperse on land, and can thus colonise managed aquatic habitats from nearby wetlands. However, whether rare phenotypes such as paedomorphs would be expressed again once aquatic conditions returned to an undisturbed fishless situation following the extirpation of alternative rare native phenotypes, is a question that remains unanswered. This leads to a second major question concerning the evolutionary conservation of polyphenisms such as facultative paedomorphosis: whether the protection of common phenotypes is a solution to maintain rare phenotypes.

Because alternative phenotypes can be environmentally driven, it is to be expected that a single genotype can lead to the whole range of phenotypes when conditions are suitable (WestEberhard 2003). However, years of selection for or against metamorphosis could prevent the resilience of paedomorphosis, i.e. its re-expression after disappearance in the population. Indeed, artificial selection experiments with a facultatively paedomorphic species of ambystomatid salamander showed that breeding metamorphic individuals together, produces progeny that are more likely to undergo metamorphosis than to reproduce as paedomorphs (Semlitsch and Wilbur 1989). A quantitative trait locus for metamorphosis timing that explains the additive effect of selection for either metamorphosis or paedomorphosis has been subsequently identified (Voss et al. 2012). In salamandrids, the potential of paedomorphs to metamorphose shows that this is a polyphenism. On another hand, the restricted geographic localisation of paedomorphs suggests the presence of a genetic cause that favours the expression of paedomorphosis versus metamorphosis. Two isolated cases in the Alpine newt (Ichthyosaura alpestris) showed the absence of resilience of paedomorphs but not of metamorphs after fish removal (Denoël et al. 2005a). Therefore, fish introductions might have caused populations to lose their potential for paedomorphosis (e.g., alleles for delayed metamorphosis: Voss et al. 2012). As shown in frogs (Vredenburg 2004; Knapp et al. 2007; Pope 2008), natural populations are thus likely to be recolonised by metamorphic dispersers, but whether the progeny of newts or salamanders could again exhibit the rare paedomorphosis developmental pathway has not been yet demonstrated in the wild. This is a crucial pattern to determine the value of conservation efforts for maintaining such uncommon or endangered phenotypes. Moreover, studying the potential for the re-expression of the paedomorphs after their extinction would then also allow a better understanding of the evolution of facultative paedomorphosis across environmental pressures (see also Bonett et al. 2014).

Many species (e.g., of Ambystomatids and Salamandrids in Europe and North America) can exhibit both paedomorphosis and metamorphosis within the same population (i.e., facultative paedomorphosis). However, there are not much geographic areas where there are a sufficient number of ponds that allows a statistical comparison of ponds with or without fish, and also those where fish have become extinct (Petranka 1998; Denoël et al. 2005a). These conditions are fulfilled on the Larzac plateau in southern France, which contains a large number of ponds that are inhabited by paedomorphic and metamorphic palmate newts (Lissotriton helveticus) and that are known to be affected by fish introductions (Denoël et al. 2005a; Denoël and Ficetola 2014, 2015). On the basis of quantitative censuses on such populations, our main aim was to test the hypothesis that paedomorphosis can show resilience, i.e., that it can be reexpressed following fish extirpation, because of the persistence of metamorphosed individuals in the environment (Denoël et al. 2005a, 2016). At a broader scale, we wanted to demonstrate the value of conservation actions such as fish removal on the re-expression of endangered phenotypes. By doing this, we also wanted to highlight the importance of maintaining both common and rare phenotypes, to conserve phenotypic diversity. 


\section{Material \& Methods}

\subsection{Study sites}

We surveyed thirty ponds in Southern Larzac plateau (Herault and Gard Department, France; between $43^{\circ} 45^{\prime} \mathrm{N}$ and $43^{\circ} 57^{\prime} \mathrm{N}$ and $3^{\circ} 16^{\prime} \mathrm{E}$ and $3^{\circ} 33^{\prime} \mathrm{E}$ ) during the peak of the breeding season (April-June 2014), i.e. when the highest abundances of the newt phenotypes can be found (Denoël and Ficetola 2014). Larzac is a traditional agricultural area, part of the Mediterranean Basin hotspot (Durand-Tullou 1959). All ponds were located within the distribution range of both paedomorphic and metamorphic palmate newts (Gabrion et al. 1977; Denoël and Ficetola 2015) (see Fig. 1a for an example of a typical pond in Larzac and Fig. 2 for a map of the area). They were classed in three categories (hereafter pond type): ten ponds (hereafter control ponds) have never been reported to have contained fish (Gabrion et al. 1977; Denoël and Ficetola 2014); ten ponds (hereafter extirpation ponds) had fish that were extirpated by conservation management (i.e., removal, $n=4)$ or natural disappearance $(n=6)$ between 2000 and 2006; and ten ponds (hereafter fish ponds) had fish present during the 2014 survey (Supplementary Table 1). Previous visits to the fish ponds showed that they also contained fish in the period 2001-2013 (Denoël and Ficetola 2014). The presence of fish in extirpation ponds was also determined by our own previous field observations for eight ponds and by local reports for two ponds (Rondeau et al. 2000) (Supplementary Table 1). All of the studied ponds were selected to have adequate features (except fish presence in fish ponds) to sustain newt populations and paedomorphs, following our previous results on the ecology of palmate newts in Larzac (Denoël and Lehmann 2006; Denoël and Ficetola 2014). This means that temporary and recently built ponds were not included in this study.

Fig. 1. A typical pond from Larzac, France (a), in which paedomorphosis in the palmate newt (Lissotriton helveticus) (b) was expressed in progenies of metamorphs after fish extirpation.

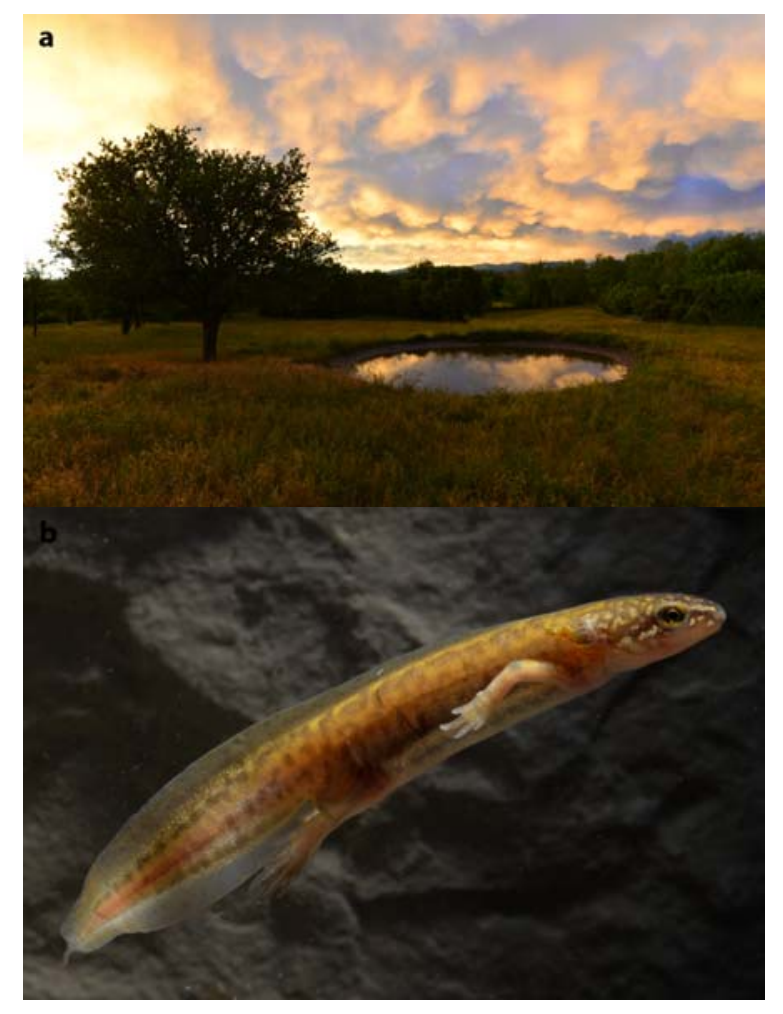


Fig. 2. Location of the three types of studied ponds in Larzac (France): control ponds devoid of fish (circles), extirpation ponds where fish disappeared (triangles) and ponds where fish were present during the survey (squares). Open and full symbols refer to ponds in which paedomorphic palmate newts were absent and present during the present survey, respectively. See supplementary table 1 for details on each pond. The Universal Transverse Mercator coordinates are shown (in $\mathrm{km}$ ). The background of the map represents the relief (the lowest elevations are darker). The interrupted traits represent the boundaries between administrative departments (Hérault, Gard and Aveyron).

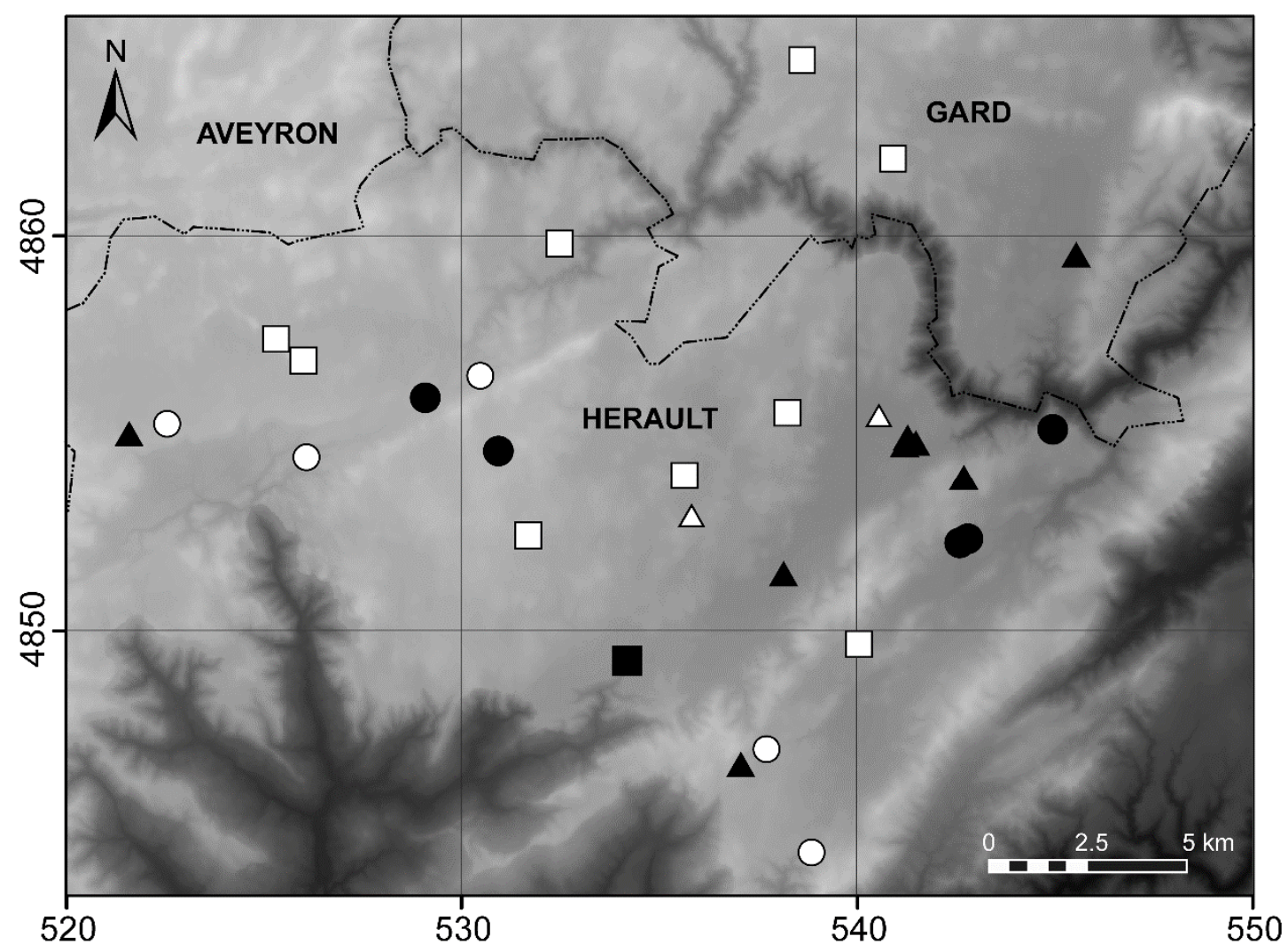

\subsection{Newt sampling}

An index of abundance of the two phenotypes was determined once for each pond by using blind dip-netting sweeps over the entire surface of each pond for exactly $2 \mathrm{~h}$ with two persons involved at the same time. During censuses, newts were placed in tanks filled with pond water, and then counted and identified according to phenotype. Paedomorphs differ from metamorphs by multiple traits, such as the presence of gills and gill slits (Fig. 1b). Their adulthood was established by the presence of a developed cloaca. Newts were released into their capture pond on the same day. The aim was not to determine population sizes but to obtain a comparable estimate of abundances across the three pond types and particularly to determine whether paedomorphosis could be expressed in ponds in which fish were extirpated. All material was washed and disinfected between each pond sampling and far from the ponds.

\subsection{Habitat features}

Three aquatic habitat features were measured at the time of sampling: water depth at the deepest part of ponds, water surface area, and concentration in dissolved oxygen (HQ30 HachLange with LDO outdoor sensor). We selected these three variables to control for their effect 
when assessing the effect of the core variable: pond type (see below). Indeed, previous ecological modeling showed that paedomorphs are primarily favoured in deep and oxygenated waters (Denoël and Ficetola 2014). It is also likely that abundances depend on the size of wetlands (Joly et al. 2001). Because previous ecological modeling showed the low effect of terrestrial variables on the distribution and abundance of paedomorphic palmate newts in Larzac (Denoël and Ficetola 2014, 2015), only aquatic variables were taken into account in this study. Although some barriers were present in Larzac, they were located only at the edges of the plateau and consequently did not prevent potential recolonizations. Geographic coordinates of ponds were obtained from aerial orthoimages (Institut Géographique National, France, $0.5 \mathrm{~m}$ resolution). Our previous research in Larzac (2001-2013) allowed us to determine the exact distribution of paedomorphs in the area (Denoël and Ficetola 2015). We then used these distribution data to determine the potential effect of the distance to the closest pond inhabited by palmate newts on the abundances of paedomorphic and metamorphic newts found after fish removal in the present study. Indeed, previous authors found that the proximity of nearby source populations could influence the probability of resilience of organisms (Knapp et al. 2001).

\subsection{Statistical analyses}

We used generalised linear models (GLMs), using an identity link and a Gaussian error distribution, to determine the main effects of pond type ( $n=3$ categories), the three pond variables (maximum water depth, pond surface area, and oxygen content) and the distance between the pond and the nearest pond inhabited by palmate newts (fixed variables) on the index of abundance of paedomorphs and metamorphs. We used the square-root of the abundance values to meet the assumptions of normality (Shapiro-Wilk's tests, all $P>0.07$ ). The residuals in the models were not spatially auto-correlated (Moran's $I, P>0.42$ ), which allowed standard GLM procedures to be used (Dormann et al., 2007). The environmental variables are used here only to control our predictions concerning newt abundance in the three pond types (Denoël and Ficetola 2014). The three aquatic predictor variables were not highly correlated (all $r<0.5$ ), allowing them to be used in the same model and did not differ significantly between pond types (One-way ANOVAs: water depth: $F_{2,27}=0.15, P=0.87$; surface area: $F_{2,27}=1.95, P=0.16$ and oxygen content: $\left.F_{2,27}=2.19, P=0.13\right)$. The water depth, surface area and oxygen content had mean \pm SE values of $1.11 \pm 0.07 \mathrm{~m}, 211.61 \pm 35.58 \mathrm{~m}^{2}$ and $9.72 \pm 0.45 \mathrm{mg} / \mathrm{L}$, respectively). No significant difference was also observed between pond types on the distance between the studied ponds and the nearest pond inhabited by palmate newts (mean \pm SE: $1000.37 \pm 99.08 \mathrm{~m} ; F_{2,27}=0.62, P=0.55$ ). We did not include the sampling dates in the models, to avoid too many descriptors, which is not recommended (Ficetola et al. 2014). The sampling date did not differ significantly between pond types $\left(F_{2,27}=2.83, P=\right.$ $0.08)$ and did not affect the index of abundance of palmate newts $\left(F_{1,28}=0.008, P=0.93\right.$ and $F_{1,28}=0.737, P=0.40$ for metamorphs and paedomorphs, respectively).

We then used an information-theoretic approach based on the Akaike Information Criterion (AIC), to rank the competing models (Burnham and Anderson 2002). Parsimonious models that explain the most variation have the lowest AIC values and are considered to be the best models. We performed automated model selection with all possible combinations. We computed the AIC corrected for small sample sizes $(\mathrm{AIC})$ and for each candidate model, we calculated the Akaike weight $w$ and the importance of the parameters (the sum of the weight of all models including the given parameter), which can be interpreted as the probability that a predictor belongs to the best model (Burnham and Anderson 2002). Finally, we used the modelaveraging function from the AIC analyses. This model-averaging procedure consists of making inferences based on the set of candidate models (with a delta AICc $<4$ ), instead of basing the conclusions only on the single best model (Mazerolle 2006). This procedure computes a weighted mean of the parameter estimates to be calculated, such that little weight is given to 
parameter estimates from models that contribute little information about the variance of the response variable (Grueber et al. 2011). Once the model-averaged estimates are calculated, the $95 \%$ confidence intervals are used to assess the magnitude of the effect: there is a strong effect when the confidence interval excludes zero (Mazerolle 2006).

To focus on the abundances of paedomorphs and metamorphs within extirpation ponds, we determined the effect of the distance between the nearest pond that contained either paedomorphs or metamorphs and the extirpation ponds, on the index of abundance, using a linear regression.

For all statistical tests, we chose an a priori level of significance of 0.05 . All analyses were performed in R 3.0.2 (www.r-project.org) using lme4 and MuMIn packages.

\section{Results}

Metamorphic and paedomorphic individuals were found in $100 \%$ and $50 \%$ of control ponds, in $90 \%$ and $80 \%$ of extirpation ponds and in $40 \%$ and $10 \%$ of fish ponds, respectively ( $n=10$ ponds by category; Fig. 3; Supplementary Table 1), respectively. Three fish species were found in fish ponds during the survey: mainly the goldfish (Carassius auratus), but also the mosquitofish (Gambusia affinis) and the pumkinseed (Lepomis gibbosus) (Supplementary Table 1). Only a few newts were found in coexistence with fish: three paedomorph in one case and between one and 13 metamorphs in the four other cases. In contrast, up to 372 metamorphs and 128 paedomorphs were caught in extirpation ponds and up to 561 metamorphs and 155 paedomorphs in control ponds (Supplementary Table 1; Fig. 3).

Fig. 3. Index of abundance (mean \pm SE) of metamorphic and paedomorphic palmate newts (Lissotriton helveticus) in three kinds of ponds in Larzac (France) $(n=30)$ : control ponds devoid of fish (white bar), extirpation ponds were fish disappeared (light grey bar) and fish ponds where fish were present during the survey (dark grey bar). See Table 1 for the results on the model averaging procedure.

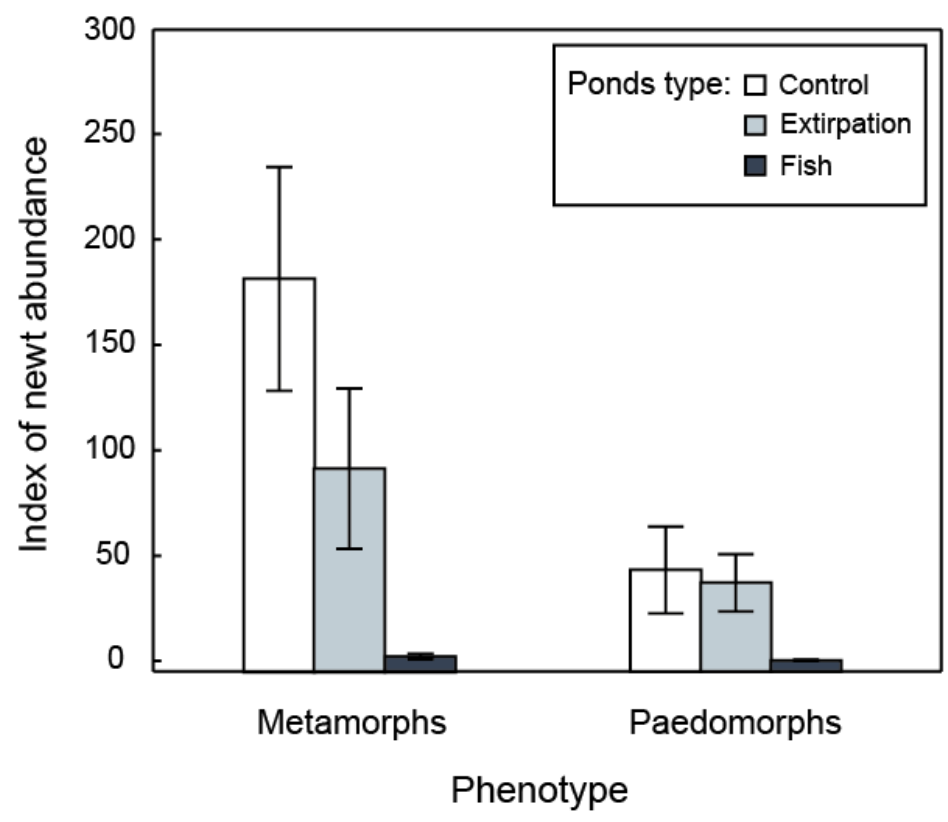


In model building, all parameters were included in at least one of the AICc best models (i.e., $\triangle \mathrm{AIC} \leq 4$ ), for both the paedomorphs and the metamorphs (Supplementary Table 2). Pond type was selected in all of the eight best models for metamorphs and in eight of the nine best models for paedomorphs, whereas the environmental covariates (pond area, water depth, oxygen content and distance to the neighboring population) were selected only in some candidate models (Supplementary Table 2). Pond type had the highest importance (i.e. the sum of Akaike weights) in explaining the index abundances ( $>0.99$ in metamorphs, 0.94 in paedomorphs: Supplementary Table 2). The model averaging procedure confirmed the effect of pond type for both phenotypes: there were significantly fewer metamorphic and paedomorphic palmate newts in fish ponds than in control and extirpation ponds (Table 1, Fig. 3 ). There were also significantly less metamorphs in extirpation ponds than in control ponds and the same abundance of paedomorphs in these two types of ponds (Table 1, Fig. 3). However, the model averaging procedure did not show any effect of the other pond characteristics (i.e., area, water depth and oxygen content), nor the distance to the nearest pond inhabited by newts on the index of newt abundance (Table 1). More particularly, the distances (mean $\pm \mathrm{SE}$ ) between the extirpation ponds and the nearest ponds that contained paedomorphs and metamorphs were $1.8 \pm 0.5 \mathrm{~km}$ and $1.2 \pm 0.2 \mathrm{~km}$, respectively. There were no significant effects of these distance values on the abundance of paedomorphs in the extirpation ponds ( $v S$ the closest pond with paedomorphs and metamorphs: $R^{2}=0.05, F_{1,8}=0.41, P=0.54 ; R^{2}=0.06$, $F_{1,8}=0.55, P=0.48$, respectively) and metamorphs ( $v s$ the closest pond with paedomorphs and metamorphs: $R^{2}=0.03, F_{1,8}=0.26, P=0.63 ; R^{2}=0.001, F_{1,8}=0.01, P=0.92$, respectively).

Table 1 Summary results of average GLM models relating the relative abundance of metamorphs and paedomorphs of palmate newts to environmental parameters. The parameters considered in the best models (with a $\triangle \mathrm{AICc}<4$ : see Supplementary Table 2) were pond type (control, extirpation and fish ponds), pond area, water depth, oxygen content $\left(\mathrm{O}_{2}\right)$ and distance to the nearest pond inhabited by palmate newts (Distance).

\begin{tabular}{lllll}
\hline Response variables & Parameters & Estimate & SE & $95 \% \mathrm{Cl}$ \\
\hline $\begin{array}{l}\text { Metamorph } \\
\text { abundance }\end{array}$ & Pond type: control vs fish & 11.07 & 2.35 & $6.250,15.891$ \\
& Pond type: extirpation vs fish & 6.01 & 2.44 & $0.347,10.829$ \\
& Pond type: extirpation vs control & -5.06 & 2.33 & $-9.838,-0.286$ \\
& Area & -0.005 & 0.005 & $-0.016,0.005$ \\
& Water depth & -0.018 & 0.025 & $-0.069,0.034$ \\
& O $_{2}$ & -0.596 & 0.408 & $-1.435,0.244$ \\
& Distance & 0.0001 & 0.002 & $-0.004,0.004$ \\
Paedomorph & Pond type: control vs fish & 3.927 & 1.748 & $0.106,8.09$ \\
abundance & Pond type: extirpation vs fish & 5.056 & 1.828 & $1.832,9.977$ \\
& Pond type: extirpation vs control & -1.13 & 1.84 & $-2.152,5.766$ \\
& Area & -0.006 & 0.004 & $-0.017,0.002$ \\
& Water depth & 0.003 & 0.022 & $-0.033,0.059$ \\
& O $_{2}$ & 0.062 & 0.317 & $-0.588,0.754$ \\
& Distance & -0.0002 & 0.002 & $-0.003,0.003$ \\
\hline
\end{tabular}




\section{Discussion}

The present study shows that the resilience of paedomorphosis, i.e. its re-expression after disappearance, is possible in amphibians when the threat, i.e., the presence of fish, is removed. Thus, this provides the potential to maintain this unique example of intraspecific diversity in newts and salamanders. In addition to reports showing that paedomorphosis could be both locally or globally at the edge of extinction in some species (Whiteman and Howard 1998; Denoël et al. 2005a; Valiente et al. 2010; Zambrano et al. 2010), the possibility of the reexpression or persistence of this alternative developmental process following fish eradication has important conservation implications. This shows the value of managing wetlands that have been historically inhabited by rare phenotypes such as paedomorphs, even when these have disappeared due to fish introductions. At a broader scale, this highlights the need to protect common phenotypes, such as metamorphs of faculatively paedomorphic species of newts and salamanders, to restore polyphenisms and thus, phenotypic diversity.

\subsection{Resilience of newts and re-expression of paedomorphosis}

Facultative paedomorphosis is a polyphenism that is geographically clustered in only a part of each species distribution range (Healy 1974; Petranka 1998; Denoël 2007). For instance, Larzac represents only $0.5 \%$ of the distribution of the palmate newt but hosts almost all known populations with paedomorphs (Denoël 2007; Geniez and Cheylan 2012; Sillero et al. 2014). This thus means that such areas have high potential for allowing resilience (i.e., the return of the state of the populations before their decline) when target habitats have been altered and paedomorphs locally extirpated. Resilience could thus be possible by a combination of favourable aquatic habitats for its expression and by the colonization of restored habitats by dispersal phenotypes, the metamorphs, that can give birth to progenies becoming paedomorphic (paedomorphs cannot migrate between ponds in Larzac). Our results are in agreement with those reported for ambystomatids, where experimental populations of metamorphs produced paedomorphs (Semlitsch and Wilbur 1989). This supports the idea that salamandrid metamorphs could carry alleles favouring the expression of paedomorphosis, as shown in ambystomatids (Voss et al. 2012). However, variations have been reported across taxa, implying the need to explore specifically the genetics of paedomorphosis in salamandrids (Johnson and Voss 2013).

In contrast to another model system (Knapp et al. 2001), we did not find a significant effect of neighbouring populations on the abundances of metamorphs and paedomorphs in ponds where fish disappeared. Larzac ponds inhabited by facultatively paedomorphic newts are not so distant from extirpation ponds, making recolonization possible. Previous ecological modeling studies highlighted the importance of surrounding palmate newt populations within a radius of $1.2 \mathrm{~km}$ to explain abundances at core ponds (Denoël and Lehmann 2006). The present results suggest that newts could have come from ponds up to $2 \mathrm{~km}$ as this was the closest distance between a studied extirpation pond and another remaining palmate newt population. Many ponds in Larzac are separated by such distances and inhabited by newts, which also shows that long distance dispersal is possible in this species. It has to be noted that all ponds in the area are perfectly known and thus the colonizers could not have come from closer sites (Denoël and Ficetola 2015). However, it cannot be excluded that a few metamorphs subsisted in some of the fish ponds before fish extirpation. In contrast, paedomorphs could not have persisted in so many cases, as occurrence with fish is very rare (less than $10 \%$ : Denoël \& Ficetola, 2014) and here paedomorphs were found in $80 \%$ of the extirpation ponds. 
Aquatic ecosystems have been shown to recover after only a certain number of years subsequently to threat removal (Knapp et al. 2001). However, amphibians could rapidly recover, reaching the same population sizes as in control lakes in only a few years (Funk and Dunlap 1999; Vredenburg 2004; Knapp et al. 2007; Pope 2008). The exact dates of fish introduction and extirpation are not known for all sites in Larzac. However, in the seventies in Larzac, only one pond out of 85 (i.e., $1.2 \%$ ) contained fish (Gabrion et al. 1977). Interviews of locals were consistent in that fish were only recently introduced, mostly in the 90 s and in the early 2000s. Extirpation took place mainly in the first decade of the 21 st century (after 2000 to 2010 according to the last available observations of fish: Supplementary Table 1). In four cases, this was done through local actions (temporary drying of the ponds and fish removal) whereas in the others, fish did not sustain and disappeared by themselves, possibly because of unsuitable aquatic conditions. A period of around 10 years between fish extirpation and the observed resilience of metamorphs and metamorphs during our survey is in agreement with the results from other authors on the timing of resilience of organisms such as amphibians (Knapp et al. 2001). The shortest recovery time for paedomorphic palmate newt found in this study was four years, but we cannot reject potential faster rates. Determining the exact dynamics of paedomorphosis is an exciting perspective of the present results but would require the experimental removal of fish across a large number of ponds and regular subsequent surveys over a period of 5 to 10 years (see e.g. Vredenburg, 2004).

The very high expression of paedomorphosis $(80 \%)$ after fish disappearance was not expected, as a previous study showed that paedomorphs are present in only $22 \%$ of Larzac ponds (Denoël and Ficetola 2015). The high rate is in large part due to the choice of ponds that presented suitable traits for paedomorphosis expression (Denoël and Ficetola 2014). It is therefore expected that small pools such as garden ponds in which fish are removed would not be associated with the subsequent appearance of paedomorphs (Denoël et al. 2016). Moreover, after fish extirpation, it was shown that amphibians can have fast increases of population sizes and then a slow decrease until they are stabilised (Knapp et al. 2007). Density affects the expression of paedomorphosis in newts and salamanders: the higher the density, the lower the number of larvae becoming paedomorphic is (Harris 1987; Semlitsch 1987). It can thus be hypothesised that fish extirpation would have enabled particularly favourable habitats for the establishment of a large number of paedomorphs, but, after reaching some critical population sizes, their numbers could be reduced.

Strictly speaking, resilience refers to the ability of an organism or ecosystem to return to its previous configuration once the perturbation is removed (Knapp et al. 2001). Unfortunately, historical data on paedomorphic populations were unavailable for all of the studied sites. Historical observations (Gabrion et al. 1977; M. Denoël, pers. obs.) reported paedomorphs before fish introductions in four out of the 10 extirpation ponds. These cases refer to true resilience because paedomorphs were again present in the ponds after threat removal. The other cases could be either such resilience or the first expression of paedomorphosis. However, it is likely that paedomorphosis was also present historically in these sites as the process appeared soon after fish extirpation and no major features other than fish seemed to have been modified.

\subsection{Conservation of common phenotypes}

An additional lesson from the observed resilience of paedomorphosis is that maintaining intraspecific diversity such as polyphenism involves protecting both common and rare phenotypes. Each phenotype can allow subsistence of the polyphenism in case of environmental 
changes and thus has some potential to maintain phenotypic variation once favourable conditions are met again for the different phenotypes (Emel and Bonett 2011). Therefore, even if a species is not globally threatened, protecting intraspecific diversity involves taking care of both endangered and non-threatened phenotypes. In many cases, alternative fishless habitats are available within dispersal capabilities of newts or salamanders (Denoël et al. 2016). The presence of common phenotypes in such habitats could thus be a key to maintain a stock of individuals that could give birth to progenies expressing the rare phenotype once favourable conditions are again met. Preserving these habitats or creating new ones therefore have high potentials.

Few conservation programmes have targeted paedomorphs. The best-known example concerns the axolotl, which is at the edge of extinction in Mexico, where management has consisted of maintaining fishless channels and increasing fishing pressure, to relax the detrimental pressures on axolotls as much as possible (Valiente et al. 2010; Von Bertrab and Zambrano 2010). In contrast to facultatively paedomorphic species, the axolotl cannot unfortunately benefit from protecting a more common phenotype. However, the present results concerning paedomorphic palmate newts are encouraging for the actions currently performed for the axolotl, as they show that removing threats can allow the persistence of paedomorphosis. In the case of the isolated axolotl in his native Mexican lake, this might involve re-introduction programmes (Zippel et al. 2011).

\subsection{Resistance}

The present study shows the low resistance of both metamorphic and paedomorphic newts to fish introductions. This supports several correlative environmental studies, which suggested that fish habitats are not suitable for many amphibians (Knapp 2005; Orizaola and Braña 2006; Pilliod et al. 2010). This confirms the results of our 2002 survey, which showed that paedomorphosis was not expressed in fish ponds (four out of 10 fish ponds were the same in both studies: Denoël et al. 2005a).

The fish invaders can have both consumptive and non-consumptive effects on native species such as amphibians (Finlay and Vredenburg 2007; Winandy and Denoël 2013). In Larzac, we mainly found goldfish to be present in ponds, but also pumpkinseed to a lesser extent (Supplementary Table 1; Denoël et al. 2005a), whereas single cases of other species introductions have also been reported (Rondeau et al. 2000). Pumpkinseeds are ferocious predators that can affect all aquatic life stages of amphibians (Parris et al. 2001; Hartel et al. 2007; Tomeček et al. 2007; Bruslé and Quignard 2013). These fish are often present at high densities, forage in the varied aquatic microhabitats, and are also aggressive towards large amphibians such as frogs (Almeida et al. 2014). Goldfish are also often numerous in ponds, but in contrast to pumpkinseeds, they are omnivorous and forage on a large variety of food sources (Richardson et al. 1995; Bruslé and Quignard 2013); however, their gape size limitations usually prevent them from preying on most adult amphibians. The consumptive effects of goldfish on amphibians are often limited to predation on the egg and larval stages, as shown for ambystomatid salamanders (Monello and Wright 2001). Non-consumptive effects on adult amphibians such as palmate newts have been shown: goldfish induce behavioural avoidance and negatively affect reproductive and foraging activities, as well as the expression of sexual ornaments (Winandy and Denoël 2015a,b; Winandy et al. 2015). The most striking response of newts to the presence of goldfish was to leave water for land and then forego breeding (Winandy et al. 2015). The newts that remained in the water with the goldfish used more aquatic shelters than in the absence of fish. Paedomophs show a stronger avoidance behaviour than 
metamorphs: in the presence of fish, paedomorphic palmate newts foraged less than metamorphs (Winandy and Denoël 2015b). In another model system, i.e., ambystomatid salamanders coping with trout cues, fewer salamander larvae became paedomorphic in a risky habitat (Jackson and Semlitsch 1993). These data together can explain the scarcity of coexistence patterns between fish and newts. On the another hand, despite their potential ability to escape from fish habitats, metamorphs are also likely to be found in these invaded habitats, because of their transient use of aquatic habitats (Perret et al. 2003; Kopecky et al. 2010).

The absence or very low abundance of newts in the studied fish ponds is most likely primarily due to the presence of fish, rather than due to other environmental variables, such as pond size, water depth, oxygen availability or the distance to another newt population that could act as source. Indeed, the inclusion of such variables within the models did not affect our conclusions. This is not surprising here, because these variables did not differ in the studied ponds (see Denoël \& Ficetola 2014 and Denoël \& Lehmann 2006 for an analysis of the effect of these variables on a large range of habitat features). In other systems, paedomorphs have been shown to coexist with predators such as crayfish, because they hide using a different streambed structure than their potential predator (Martin et al. 2012). The pond substrate in Larzac does not allow this partitioning, but future study should analyse the importance of microhabitat diversity on the possible maintenance of both newt phenotypes in syntopy.

\subsection{Conclusions}

Conservation management at times where so many detrimental pressures are acting is a difficult task. Because of funding and logistic constraints, priorities are needed (Restani and Marzluff 2001). Determining the effectiveness of actions is a valuable pre-requisite to justify managements and obtain supports from conservation and governmental agencies (Austin et al. 2015). Showing resilience of common and rare target organisms subsequently to threat removal is one of the key points in this context. Future works should then more deeply evaluate the value of conservation recommendations so to address as much efficiently as possible biodiversity requirements in integrating the specificities of intra-specific variations.

\section{Acknowledgements}

We are grateful to three anonymous reviewers for their constructive comments on the manuscript, N. Belleuvre, A. Glavet, and B. Lejeune for their support in the field, G. Hanula and M. Salze for sharing their observations, to the land owners and municipalities for allowing access to their ponds, to Institut Géographique National for providing maps. Capture permits were obtained from DREAL Languedoc Roussillon. The scientific and ethical aspects of the protocol were approved by the Conseil National de la Conservation de la Nature (France). This research was supported by the Fonds de la Recherche Scientifique - FNRS under grant number J.008.13 and by the University of Liège under a Fonds Spéciaux grant number C11/23. M. Denoël and L. Winandy are respectively a Senior Research Associate and a Research Fellow at F.R.S. - FNRS. This is a publication of the Applied and Fundamental Fish Research Center (AFFISH-RC). The authors declare they have no conflict of interest.

\section{References}

Almeida, D., Merino-Aguirre, R., Vilizzi, L., Copp, G.H., 2014. Interspecific aggressive behaviour of invasive pumpkinseed Lepomis gibbosus in Iberian fresh waters. PLoS ONE 9, e88038. 
Austin, Z., McVittie, A., McCracken, D., Moxey, A., Moran, D., White, P.C.L., 2015. Integrating quantitative and qualitative data in assessing the cost-effectiveness of biodiversity conservation programmes. Biodivers. Conserv. 24, 1359-1375.

Baker, J.A., Wund, M.A., Chock, R.Y., Ackein, L., Elsemore, R., Foster, S.A., 2010. Predation history and vulnerability: Conservation of the stickleback adaptive radiation. Biol. Conserv. 143, 1184-1192.

Bonett, R.M., Steffen, M.A., Lambert, S.M., Wiens, J.J., Chippindale, P.T., 2014. Evolution of paedomorphosis in plethodontid salamanders: Ecological correlates and re-evolution of metamorphosis. Evolution 68, 466-482.

Bruslé, J., Quignard, J.-P., 2013. Biologie des Poissons d'Eau douce européens. 2nd edition. Lavoisier, Paris, France.

Burnham, K.P., Anderson, D.R., 2002. Model Selection and Multimodel Inference: a Practical Information-Theoretic Approach. Springer Verlag, New York.

Cambray, J.A., 2003. Impact on indigenous species biodiversity caused by the globalisation of alien recreational freshwater fisheries. Hydrobiologia 500, 217-230.

Contreras, V., Martinez-Meyer, E., Valiente, E., Zambrano, L., 2009. Recent decline and potential distribution in the last remnant area of the microendemic Mexican axolotl (Ambystoma mexicanum). Biol. Conserv. 142, 2881-2885.

Cox, J.G., Lima, S.L., 2006. Naiveté and an aquatic-terrestrial dichotomy in the effects of introduced predators. Trends Ecol. Evol. 21, 674-680.

Denoël, M., 2007. Priority areas of intraspecific diversity: Larzac, a global hotspot for facultative paedomorphosis in amphibians. Anim. Cons. 10, 110-118.

Denoël, M., Džukić, G., Kalezić, M.L., 2005a. Effect of widespread fish introductions on paedomorphic newts in Europe. Conserv. Biol. 19, 162-170.

Denoël, M., Ficetola, G.F., 2014. Heterochrony in a complex world: Disentangling environmental processes of facultative paedomorphosis in an amphibian. J. Anim. Ecol. 83, 606-615.

Denoël, M., Ficetola, G.F., 2015. Using kernels and ecological niche modeling to delineate conservation areas in an endangered patch-breeding phenotype. Ecol. Appl. 25, 19221931.

Denoël, M., Lehmann, A., 2006. Multi-scale effect of landscape processes and habitat quality on newt abundance: implications for conservation. Biol. Conserv. 130, 495-504.

Denoël, M., Scime, P., Zambelli, N., 2016. Newt life after fish introduction: extirpation of paedomorphosis in a mountain fish lake and newt use of satellite pools. Curr. Zool. 62, in press.

Denoël, M., Whiteman, H.H., Joly, P., 2005b. Evolutionary ecology of facultative paedomorphosis in newts and salamanders. Biol. Rev. 80, 663-671.

Dormann, C.F., McPherson, J.M., Araujo, M.B., Bivand, R., Bolliger, J., Carl, G., Davies, R.G., Hirzel, A., Jetz, W., Kissling, W.D., Kühn, I., Ohlemüller, R., Peres-Neto, P.R., Reineking, B., Schröder, B., Schurr, F.M., Wilson, R., 2007. Methods to account for spatial autocorrelation in the analysis of species distributional data: a review. Ecography 30, 609-628.

Durand-Tullou, A., 1959. Un Millieu de Civilisation traditionnelle. Le Causse de Blandas. Published PhD Thesis. Faculté des Lettres et Sciences Humaines de Montpellier. Edition du Bedfroie, Millau, France

Emel, S.L., Bonett, R.M., 2011. Considering alternative life history modes and genetic divergence in conservation: A case study of the Oklahoma salamander. Conserv. Genet. 12, 1243-1259. 
Ficetola, G.F., Bonardi, A., Mucher, C.A., Gilissen, N.L.M., Padao-Schipoa, E., 2014. How many predictors in species distribution models at the landscape scale? Land use versus LiDAR-derived canopy height. Int. J. Geo. Inf. Sci. 28, 1723-1739.

Finlay, J.C., Vredenburg, V.T., 2007. Introduced trout sever trophic connections in watersheds: Consequences for a declining amphibian. Ecology 88, 2187-2198.

Fraser, D.J., Bernatchez, L., 2001. Adaptive evolutionary conservation: towards a unified concept for defining conservation units. Conserv. Biol. 10, 2741-2752.

Funk, W.C., Dunlap, W.W., 1999. Colonization of high elevation lakes by long-toed salamanders (Ambystoma macrodactylum) after the extinction of introduced trout populations. Can. J. Zool. 77, 1759-1767.

Gabrion, J., Sentein, P., Gabrion, C., 1977. Les populations néoténiques de Triturus helveticus Raz. des Causses et du Bas-Languedoc. I. Répartition et caractéristiques. Terre Vie 31, 489-506.

Geniez, P., Cheylan, M., 2012. Les Amphibiens et les Reptiles du Languedoc-Roussillon et Régions limitrophes. Atlas biogéographique. Biotope and Museum National d'Histoire Naturelle, Mèze and Paris.

Gould, S.J., 1977. Ontogeny and Phylogeny. Harvard University Press, Harvard.

Grueber, C.E., Nakagawa, S., Laws, R.J., Jamieson, I.G., 2011. Multimodel inference in ecology and evolution: Challenges and solutions. J. Evol. Biol. 24, 699-711.

Harris, R.N., 1987. Density-dependent paedomorphosis in the salamander Notophthalmus viridescens dorsalis. Ecology 68, 705-712.

Hartel, T., Nemes, S., Cogalniceanu, D., Ollerer, K., Schweiger, O., Moga, C., Demeter, L., 2007. The effect of fish and aquatic habitat complexity on amphibians. Hydrobiologia 583, 173-182.

Healy, W.R., 1974. Population consequences of alternative life histories in Notophthalmus $v$. viridescens. Copeia 1974, 221-229.

Hendry, A.P., Grant, P.R., Rosemary Grant, B., Ford, H.A., Brewer, M.J., Podos, J., 2006. Possible human impacts on adaptive radiation: beak size bimodality in Darwin's finches. Proc. Roy. Soc. B: Biol. Sci. 273, 1887-1894.

Jackson, M.E., Semlitsch, R.D., 1993. Paedomorphosis in the salamander Ambystoma talpoideum: Effects of a fish predator. Ecology 74, 342-350.

Johnson, C.K., Voss, S.R., 2013. Salamander paedomorphosis. Linking thyroid hormone to life history and life cycle evolution, in: Y.-B. Shi (Ed), Current Topics in Developmental Biology, vol. 103, Animal Metamorphosis. Academic Press, Burlington, pp. 229-258.

Joly, P., Miaud, C., Lehmann, A., Grolet, O., 2001. Habitat matrix effects on pond occupancy in newts. Conserv. Biol. 15, 239-248.

Kats, L.B., Ferrer, R.P., 2003. Alien predators and amphibian declines: review of two decades of science and the transition to conservation. Diversity Distrib. 9, 99-110.

Knapp, R.A., 2005. Effects of nonnative fish and habitat characteristics on lentic herpetofauna in Yosemite National Park, USA. Biol. Conserv. 121, 265-279.

Knapp, R.A., Boiano, D.M., Vredenburg, V.T., 2007. Removal of nonnative fish results in population expansion of a declining amphibian (mountain yello-legged frog, Rana muscosa). Biol. Conserv. 135, 11-20.

Knapp, R.A., Matthews, K.R., Sarnelle, O., 2001. Resistance and resilience of alpine lake fauna to fish introductions. Ecol. Monogr. 71, 401-421.

Kopecky, O., Vojar, J., Denoël, M., 2010. Movements of Alpine newts (Mesotriton alpestris) between small aquatic habitats (ruts) during the breeding season. Amphibia-Reptilia 31, 109-116.

Lescak, E.A., von Hippel, F.A., 2011. Selective predation of threespine stickleback by rainbow trout. Ecol. Freshwat. Fish 20, 308-314. 
Martin, S.D., Harris, B.A., Collums, J.R., Bonett, R.M., 2012. Life between predators and a small space: Substrate selection of an interstitial space-dwelling stream salamander. J. Zool. 287, 205-214.

Mazerolle, M.J., 2006. Improving data analysis in herpetology: using Akaike's Information Criterion (AIC) to assess the strength of biological hypotheses. Amphibia-Reptilia 27, 169-180.

McGeoch, M.A., Butchart, S.H.M., Spear, D., Marais, E., Kleynhans, E.J., Symes, A., Chanson, J., Hoffmann, M., 2010. Global indicators of biological invasion: Species numbers, biodiversity impact and policy responses. Diversity Distrib. 16, 95-108.

Monello, R.J., Wright, R.G., 2001. Predation by goldfish (Carassius auratus) on eggs and larvae of the eastern long-toed salamander (Ambystoma macrodactylum columbianum). J. Herpetol. 35, 350-353.

Moritz, C., 2002. Strategies to protect biological diversity and the evolutionary processes that sustain it. Syst. Biol. 51, 238-254.

Orizaola, G., Braña, F., 2006. Effect of salmonid introduction and other environmental characteristics on amphibian distribution and abundance in mountain lakes of northern Spain. Anim. Cons. 9, 171-178.

Parris, M.J., Laird, C.W., Semlitsch, R.D., 2001. Differential predation on experimental populations of parental and hybrid leopard frog (Rana blairi and Rana sphenocephala) larvae. J. Herpetol. 35, 479-485.

Perret, N., Pradel, R., Miaud, C., Grolet, O., Joly, P., 2003. Transience, dispersal and survival rates in newt patchy populations. J. Anim. Ecol. 72, 567-575.

Petranka, J.W., 1998. Salamanders of the United States and Canada. Smithsonian Institution Press, Washington.

Pilliod, D.S., Hossack, B.R., Bahls, P.F., Bull, E.L., Corn, P.S., Hokit, G., Maxell, B.A., Munger, J.C., Wyrick, A., 2010. Non-native salmonids affect amphibian occupancy at multiple spatial scales. Diversity Distrib. 16, 959-974.

Pope, K.L., 2008. Assessing changes in amphibian population dynamics following experimental manipulations of introduced fish. Conserv. Biol. 22, 1572-1581.

Restani, M., Marzluff, J.M., 2001. Avian conservation under the endangered species act: Expenditures versus recovery priorities. Conserv. Biol. 15, 1292-1299.

Richardson, M.J., Whoriskeaynd, G., Roy, L.H., 1995. Turbidity generation and biological impacts of an exotic fish Carassius auratus, introduced into shallow seasonally anoxic ponds. J. Fish Biol. 47, 576-585.

Rondeau, A., Marquis, S., Morvan, R., 2000. Etat des Lieux des Connaissances des Reptiles et Amphibiens sur les Causses méridionaux. Groupe de recherche et d'information sur les vertébrés et leur environnement, unpublished report, France.

Salo, P., Korpimäki, E., Banks, P.B., Nordström, M., Dickman, C.R., 2007. Alien predators are more dangerous than native predators to prey populations. Proc. Roy. Soc. B: Biol. Sci. 274, 1237-1243.

Semlitsch, R.D., 1987. Paedomorphosis in Ambystoma talpoideum: effects of density, food, and pond drying. Ecology 68, 994-1002.

Semlitsch, R.D., Wilbur, H.M., 1989. Artificial selection for paedomorphosis in the salamander Ambystoma talpoideum. Evolution 43, 105-112.

Sillero, N., Campos, J., Bonardi, A., Corti, C., Creemers, R., Crochet, P.-A., Crnobrnja Isailović, J., Denoël, M., Ficetola, G.F., Gonçalves, J., Kuzmin, S., Lymberakis, P., de Pous, P., Rodríguez, A., Sindaco, R., Speybroeck, J., Toxopeus, B., Vieites, D.R., Vences, M., 2014. Updated distribution and biogeography of amphibians and reptiles of Europe. Amphibia-Reptilia 35, 1-31. 
Stuart, S.N., Chanson, J.S., Cox, N.A., Young, B.E., Rodrigues, A.S.L., Fischman, D.L., Waller, D.W., 2004. Status and trends of amphibian declines and extinctions worldwide. Science 306, 1783-1786.

Tomeček, J., Kováč, V., Katina, S., 2007. The biological flexibility of the pumpkinseed: a successful colonizer throughout Europe, in: F. Gherardi (Ed), Biological invaders in inland waters: Profiles, distribution, and threats. Springer, Dordrecht, The Netherlands, pp. 307-336.

Valiente, E., Tovar, A., González, H., Eslava-Sandoval, D., Zambrano, L., 2010. Creating refuges for the axolotl (Ambystoma mexicanum). Ecol. Restor. 28, 257-259.

Von Bertrab, A., Zambrano, L., 2010. Participatory monitoring and evaluation of a Mexico City wetland restoration effort. Ecol. Restor. 28, 343-353.

Von Hippel, F.A., 2008. Conservation of threespine and ninespine stickleback radiations in the Cook Inlet Basin, Alaska. Behaviour 145, 693-724.

Voss, S.R., Kump, D.K., Walker, J.A., Shaffer, H.B., Voss, G.J., 2012. Thyroid hormone responsive QTL and the evolution of paedomorphic salamanders. Heredity 109, 293298.

Vredenburg, V.T., 2004. Reversing introduced species effects: Experimental removal of introduced fish leads to rapid recovery of a declining frog. Proc. Natl. Acad. Sci. U.S.A. 101, 7646-7650.

Wake, D.B., Vredenburg, V.T., 2008. Are we in the midst of the sixth mass extinction? A view from the world of amphibians. Proc. Natl. Acad. Sci. U.S.A. 105, 11466-11473.

West-Eberhard, M.J., 2003. Developmental Plasticity and Evolution. Oxford University Press.

Whiteman, H.H., Howard, R.D., 1998. Conserving alternative amphibian phenotypes: Is there anybody out there?, in: M.J. Lannoo (Ed), The Status and Conservation of Midwestern Amphibians. Iowa University Press, Iowa City, pp. 317-324.

Winandy, L., Darnet, E., Denoël, M., 2015. Amphibians forgo aquatic life in response to alien fish introduction. Anim. Behav. 109, 209-216.

Winandy, L., Denoël, M., 2013. Introduced goldfish affect amphibians through inhibition of sexual behaviour in risky habitats: an experimental approach. PLoS ONE 8, e82736.

Winandy, L., Denoël, M., 2015a. Expression of sexual ornaments in a polymorphic species: phenotypic variation in response to environmental risk. J. Evol. Biol. 28, 1049-1056.

Winandy, L., Denoël, M., 2015b. The aggressive personality of an introduced fish affects foraging behavior in a polymorphic newt. Behav. Ecol. DOI: 10.1093/beheco/arv101.

Zambrano, L., Valiente, E., Vander Zanden, M.J., 2010. Food web overlap among native axolotl (Ambystoma mexicanum) and two exotic fishes: carp (Cyprinus carpio) and tilapia (Oreochromis niloticus) in Xochimilco, Mexico City. Biol. Invas. 12, 3061-3069.

Zippel, K., Johnson, K., Gagliardo, R., Gibson, R., McFadden, M., Browne, R., Martinez, C., Townsend, E., 2011. The amphibian Ark: A global community for ex situ conservation of amphibians. Herpetol. Conserv. Biol. 6, 340-352.

Article history:

Received 19 May 2015

Received in revised form 20 October 2015

Accepted 26 October 2015

Available online 10 November 2015 